\title{
Continuous drive friction welding of AISI 8630 low-alloy steel: experimental investigations on microstructure evolution and mechanical properties
}

\section{Amborish Banerjee ${ }^{1}$}

Advanced Forming Research Centre (AFRC), University of Strathclyde

85 Inchinnan Drive, Inchinnan, Renfrewshire, PA 4 9L, UK

amborish.banerjee@strath.ac.uk, amborishbanerjee1205@gmail.com

\section{Michail Ntovas}

Advanced Forming Research Centre (AFRC), University of Strathclyde

85 Inchinnan Drive, Inchinnan, Renfrewshire, PA 4 9L, UK

dovas13@gmail.com

\section{Laurie Da Silva}

Advanced Forming Research Centre (AFRC), University of Strathclyde

85 Inchinnan Drive, Inchinnan, Renfrewshire, PA 4 9LJ, UK

laurie.da-silva@strath.ac.uk

\section{Ryan 0' Neill}

Advanced Forming Research Centre (AFRC), University of Strathclyde

85 Inchinnan Drive, Inchinnan, Renfrewshire, PA 4 9LJ, UK

r.o-neill@strath.ac.uk

\section{Salaheddin Rahimi}

Advanced Forming Research Centre (AFRC), University of Strathclyde

85 Inchinnan Drive, Inchinnan, Renfrewshire, PA 4 9LJ, UK

salah.rahimi@strath.ac.uk

\section{ABSTRACT}

Continuous drive friction welding $(C D W)$ is a state-of-the-art solid-state welding technology for joining metallic components used in aerospace, oil and gas and power generation industries. This study summarises the results of mechanical and microstructural investigations on a modified AISI-8630 steel subjected to CDW.

\footnotetext{
${ }^{1}$ Email id: amborish.banerjee@strath.ac.uk, amborishbanerjee1205@gmail.com, Telephone: $+447594660185$
} 
Continuous drive friction welding of AISI 8630 low-alloy steel: experimental investigations on microstructure evolution and mechanical properties Journal of Manufacturing Science and Engineering

34 The effects of welding process parameters, including rotational speed, friction and forge forces, during CDW 35 were explored to determine an optimum welding condition. The mechanical properties of the weld, and

36 microstructural characteristics across different regions of the weld were measured and examined. The

37 microstructure characterisation results suggest that the weld zone (WZ) experiences temperatures above

38 the $A c_{3}$ and the thermo-mechanically affected zone (TMAZ) experiences temperatures between $A c_{1}$ and $A c_{3}$

39 of the material. Investigations with electron backscatter diffraction (EBSD) demonstrated the occurrence of

40 strain induced dynamic recrystallisation in the weld. The weld demonstrated higher yield and ultimate

41 tensile strengths at the expense of ductility and hardening capacity compared to the base metal (BM). The

42 strain hardening profiles of the welds exhibited a dual-slope characteristic, an indication of different levels

43 of plastic deformation experienced by the constituent phases (i.e., martensite, bainite and ferrite) present

44 in the microstructure. The maximum strength-to-ductility combination and static toughness values were

45 obtained for the weld produced under the highest rotational speed, maximum friction force and an

46 intermediate forge force of 1200-1400 rpm, 375-425 kN and 600-650 kN, respectively.

47 Keywords: Continuous drive friction welding, strain-induced dynamic recrystallisation, welding 48 parameters, mechanical properties, strain hardening, fracture

\section{1. INTRODUCTION}

50 Low carbon-low alloy steels are extensively used in crude oil and natural gas

51 transportation due to their superior mechanical properties. Particularly, in the offshore

52 industry where the material is exposed to critical environmental conditions, low-alloy

53 steels are mostly used in the form of forged components for subsea applications. AISI

548630 low-alloy high strength steel, due to its better weldability and optimum strength-

55 ductility combination has been widely used in oil excavation (e.g., drilling) applications

56 including block valves, hangers and connectors for oil patches [1]. These pipelines and

57 structural components are joined together by conventional welding techniques that are 
Continuous drive friction welding of AISI 8630 low-alloy steel: experimental investigations on microstructure evolution and mechanical properties Journal of Manufacturing Science and Engineering

58 prone to different modes of failure [2]. The microstructural heterogeneity of the weld

59 makes it more susceptible to crack initiation and propagation. In general, the weld

60 components are typically used under enormous service loads and exposed to critical

61 conditions (e.g., high pressure, turbulent flow). Therefore, understanding the structural

62 integrity of welds is of significant importance for a robust design of hydraulic piping

63 systems.

64 Rotary friction welding (RFW) is a solid-state joining process where two parts are

65 joined under severe shear deformation at elevated temperatures resulted from frictional

66 heat generated by the relative rotation of the faying surfaces under the application of an

67 axial force. For RFW, one of the weldment parts is rotated to a predefined rotational

68 speed, while the other side is fixed on a stationary axis and pushed against the rotating

69 side with an applied force. This leads to friction between the interface of the two

70 weldment parts and increases the temperature resulting in the softening of the material

71 and finally the weld. The weld parameters such as friction and forge forces, rotational

72 speed and friction time play major roles in altering the mechanical properties of the final

73 weld [3]. The RFW technique is classified into two categories of CDW and inertia friction

74 welding (IFW). In CDW, the rotating part is directly connected to a motor, turning at a

75 constant rpm during welding, while in IFW the rotating component is attached to a

76 flywheel which stores the kinetic energy that is transformed into frictional heat during

77 the welding process [4]. The benefits of RFW over the conventional welding methods are

78 that (a) it is a solid-state joining process and thus the formation of solidification cracks,

79 pores, and other associated defects are reduced, (b) there is no requirement for welding 
Continuous drive friction welding of AISI 8630 low-alloy steel: experimental investigations on microstructure evolution and mechanical properties Journal of Manufacturing Science and Engineering

80 flux, filler material or shielding, (c) the localised deformation and high temperature at the

81 weld interface, leads to the formation of recrystallised grains, resulting in better

82 mechanical properties compared to the BM, etc. [4].

83 Udayakumar et al. [5] investigated the mechanical properties of dual-phase (i.e.,

84 ferritic-austenitic) duplex stainless steel welds produced by CDW under variable process

85 parameters (i.e., friction pressure, upset pressure, burn-off length and rotational speed).

86 The study showed an increase in the tensile strength and hardness of the welded

87 materials that were correlated with the ferrite grain size and the volume fraction of the

88 austenite and ferrite phase. Hazra et al. [6] conducted CDW on austenitic stainless steel

89 while varying the forge force and found no significant effect on the weld's tensile

90 strength. The weld demonstrated inferior strength than that of the BM and most failures

91 were observed in the weld zone. Selvamani et al. [7] observed that the rotational speed

92 of the weld had a greater effect on the ultimate tensile strength compared to the forge

93 and friction forces during CDW of AISI 1035 steel. Sahin [8] reported an increase in the

94 tensile strength of AISI304 stainless steel welds made by CDW, with increasing friction

95 time and force up to an optimum value beyond which an adverse effect was observed. It

96 was concluded that the application of a higher friction force was creating these effects.

97 From the literature survey, it can be concluded that several research works on the

98 CDW of different grades of steel have been reported. However, limited investigations

99 have been conducted on the CDW of AISI 8630 material. This study presents the results

100 of an investigation on the effect of three critical process parameters i.e. rotational speed,

101 friction force and forge force on the mechanical properties of the weld. The evolution of 
Continuous drive friction welding of AISI 8630 low-alloy steel: experimental investigations on microstructure evolution and mechanical properties Journal of Manufacturing Science and Engineering

102 microstructure during CDW is examined and correlated with the mechanical properties

103 to establish the structure-property relationships.

\section{2. MATERIAL AND EXPERIMENTAL PROCEDURES}

AISI 8630 steel with the nominal chemical composition of $0.3 \mathrm{C}-0.96 \mathrm{Cr}-0.9 \mathrm{Mn}$ used in these investigations. The as-received material was hardened at $860^{\circ} \mathrm{C}$ for 3 hours and subsequently tempered at $680{ }^{\circ} \mathrm{C}$ for 6.5 hours followed by air cooling to room

109 temperature. The material was received in tubular form with $150 \mathrm{~mm}$ length and outer 110 and inner diameters of $80 \mathrm{~mm}$ and $40 \mathrm{~mm}$, respectively. The welding between these two 111 mating surfaces was carried out by the CDW process using a 125-ton MTI built RFW 112 machine. For the welding, one tubular part was clamped to the rotating spindle and the 113 second tubular part was stationary on the fixture. This fixture applied the desired force in

114 the axial direction for the forging stage of the process. For this study, the effects of three 115 parameters including rotational speed, friction force, and forge force were explored to 116 determine the optimum process parameters. To maintain the confidentiality of the

117 proprietary information, instead of the precise welding process parameters, a range

118 (scaled parameter) is provided for each (Table 1). A macrograph of a typical weld joint 119 highlighting the flash generated during CDW and the fixture and the spindle side, is shown 120 in Fig. 1.

121 For the post-weld metallurgical investigations, samples were extracted from the

122 weld cross-section along the axis of the welded tubular parts. The metallographic samples 123 were ground and polished to a mirror finished condition as per the ASTM E3-11 standard 
Continuous drive friction welding of AISI 8630 low-alloy steel: experimental investigations on microstructure evolution and mechanical properties Journal of Manufacturing Science and Engineering

124 [9]. The mirror-finished samples were then etched using $2 \%$ Nital followed by

125 microstructure examination using a Leica DM6000 M optical light microscope (OM) and a

126 FEI Quanta ${ }^{\text {TM }} 250$ field emission gun (FEG) scanning electron microscope (SEM) equipped

127 with a Nordlys II detector for electron backscatter diffraction (EBSD) analysis.

128 For EBSD acquisitions, samples were cut from the optimum weld joint and 129 metallographically prepared to a mirror finished condition followed by vibratory polishing

130 for $\approx 12$ hours using a colloidal silica suspension. For each sample, an EBSD scan was

131 carried out over an area of $100 \times 100 \mu \mathrm{m}^{2}$ with a step size of $0.2 \mu \mathrm{m}$ at an accelerating

132 voltage of $20 \mathrm{kV}$. The obtained maps were post-processed using HKL-channel 5 software

133 to investigate the grain size distributions and misorientation profiles.

$134 \quad$ Vickers microhardness measurements were conducted on the weld cross-sections

135 covering different regions of the welds by applying $0.2 \mathrm{kgf}$ load with a dwell time of 12

136 seconds. Microhardness contour plots were then constructed from the measured data

137 for each weld sample with $0.5 \mathrm{~mm}$ and $1.5 \mathrm{~mm}$ spacing across the weld and along the

138 thickness, respectively. Uniaxial tensile tests were conducted on the welds according to

139 ASTM E-8M standard [10] under a constant strain rate of $0.00025 / \mathrm{s}$ at ambient

140 temperature. Tensile specimens with $20 \mathrm{~mm}$ gauge length and $6 \mathrm{~mm}$ gauge diameter

141 were extracted across the axial direction (or longitudinal direction) of the weld joints with

142 the weld-zone located in the middle of the gauge section. It is worth mentioning here that

143 the gauge section consisted of all the different weld regimes i.e. WZ, TMAZ and HAZ in

144 addition to that of the BM. The experiments were performed using a screw-driven Zwick

145 Z250/SW5A testing machine calibrated with a 250-kN load cell. An extensometer with a 
Continuous drive friction welding of AISI 8630 low-alloy steel: experimental investigations on microstructure evolution and mechanical properties Journal of Manufacturing Science and Engineering

$14630 \mathrm{~mm}$ gauge length was used to measure the displacement during tensile tests. Three

147 specimens were tested for each condition to ensure repeatability and consistency in the 148 data.

The fracture surfaces of the failed tensile specimens were examined under SEM

150 to understand the effect of microstructural features on the final fracture. The size and

151 density of the dimples observed on the fracture surface were measured using ImageJ

152 image analysis software. More than 100 individual dimples, spread throughout the

153 fracture surface, were identified and their characteristics (i.e. size and density) were

154 measured using a procedure identical to the equi-circular diameter (ECD) method. The

155 slant regions of the fracture surface were not considered for measurement to minimise 156 uncertainty in the reported results.

\section{3. RESULTS AND DISCUSSION}

\section{3.1. Microstructure characterisation}

159 The microstructure appearances of the BM and different regions of the weld are

160 shown in Fig. 2. The cross-sectional macrograph of the weld shown in Fig. 2a 161 demonstrates the WZ, TMAZ, HAZ and the flash (the extruded material) during the CDW

162 from the weld interfaces. The TMAZ is the area adjacent to the $W Z$ where the 163 temperature is comparatively lower, and the HAZ is a region between the TMAZ and BM.

164 The WZ and TMAZ were comparatively much narrower than the HAZ. The microstructure 165 of the BM consisted of bainite and ferrite in the matrix along with carbide precipitates, as 166 shown in Fig. 2b. Different morphologies of bainite were observed including lower bainite, 167 upper bainite, granular bainite and plate-like bainite. The microstructure of the WZ (refer 
Continuous drive friction welding of AISI 8630 low-alloy steel: experimental investigations on microstructure evolution and mechanical properties Journal of Manufacturing Science and Engineering

168 Fig. $2 c, d)$ is dominated by martensite $(\approx 80 \%)$ with a small fraction of bainite $(\approx 15 \%)$ and

169 retained austenite $(\mathrm{RA})(\approx 5 \%)$. It is important to mention here that the provided volume

170 fraction of the available phases is purely quantitative based. Fig. $2 c$ depicts the presence

171 of RA in the WZ. This implies that the temperature in the WZ may have approached the

$172 A c_{3}$ temperature during welding. The $A c_{1}$ and $A c_{3}$ temperatures for the AISI-8630 steel

173 used in this study were calculated to be $\sim 730 \pm 20{ }^{\circ} \mathrm{C}$ and $772 \pm 15^{\circ} \mathrm{C}$, respectively. This

174 suggests that the temperature in the WZ during the welding process reached $\sim 772{ }^{\circ} \mathrm{C}$

175 where the majority of the microstructure was transformed to austenite with a small

176 fraction of remaining ferrite. This was then subjected to severe shear deformation

177 induced by the welding process. Post IFW fast cooling from this temperature resulted in

178 a transformation of the austenite to martensite and bainite, where traces of RA can also

179 be observed in the microstructure. The microstructure of the TMAZ, shown in Fig. 2e

180 demonstrates the presence of martensite, bainite and ferrite which signifies that the

181 temperature experienced in this zone was slightly lower than that of the WZ (i.e., between

$182 A C_{1}$ and $\left.A C_{3}\right)$. The increase in the fraction of bainite is an indication of the lower

183 temperature reached during CDW and the slower cooling rate of the TMAZ compared to

184 the WZ. The HAZ exhibited a similar microstructure (refer Fig. 2f) as that of the BM,

185 signifying that the temperature experienced in the $\mathrm{HAZ}$ was below $A \mathrm{c}_{1}$. Similar studies on

186 correlating the changes in the microstructure with the likely peak temperature attained

187 within different weld regions in micro-alloyed steel during friction stir welding have been

188 reported before by Rahimi et al. and Baker et al. [11, 12]. 
Continuous drive friction welding of AISI 8630 low-alloy steel: experimental investigations on microstructure evolution and mechanical properties Journal of Manufacturing Science and Engineering

EBSD maps across different regions of the CD9 weld were carried out to study the

190 microstructure morphology and the possible evolutionary mechanisms during welding.

191 The orientation image map (OIM) with inverse pole figure (IPF) colouring with respect to

192 the axial direction (AD) and the plots of misorientation angle distributions for each of the

193 weld zones are shown in Fig. 3. The BM consists of both coarse grains and lath-type

194 structures with an average size of $\approx 11.2 \mu \mathrm{m}$ (Fig. 3a,). The corresponding misorientation

195 distribution shown in Fig. $3 b$ exhibits the presence of $\approx 56 \%$ low angle grain boundaries

$196($ LAGB) and $\approx 44 \%$ high angle grain boundaries (HAGB). Note that the threshold angles of

$197 X X$ and $Y Y$ were considered for the classification of LAGB and HAGB, respectively.

198 The microstructures of the WZ and TMAZ, in comparison to the BM, were more

199 refined with a higher fraction of LAGBs which is an indication of subgrains formed via

200 dislocation cell structures. From Fig. $3 c$ and e, the average size of the randomly oriented

201 grains, as well as, laths in the WZ and TMAZ were calculated to be $\approx 7.5 \mu \mathrm{m}$ (Fig. 3c) and

$20210 \mu \mathrm{m}$ (Fig. 3e) $\mu \mathrm{m}$, respectively. The presence of refined grains in the WZ can be due to

203 the occurrence of dynamic recrystallisation at high temperatures and under severe plastic

204 deformation at the interface of the weld. This means that the frictional heat leads to the

205 transformation of the BM microstructure to austenite and then the transformed

206 austenite undergoes shear deformation during IFW. This results in strain-induced

207 dynamic recrystallisation and the formation of fine austenite grains, which on fast cooling

208 restrict the growth of laths and leads to a finer microstructure. From Fig. 3d, the fractions

209 of LAGBs and HAGBs in the WZ were calculated as $\approx 60$ and $40 \%$. While the plot of

210 misorientation angle distributions for the TMAZ (see Fig. 3f) shows $63 \%$ and $37 \%$ fractions 
Continuous drive friction welding of AISI 8630 low-alloy steel: experimental investigations on microstructure evolution and mechanical properties Journal of Manufacturing Science and Engineering

211 for LAGBs and HAGBs, respectively, the average grain/lath size is larger than that of the

212 WZ. According to Ma et al. [13], the lower fraction of LAGBs in the WZ is due to the

213 gradients in the plastic deformation, temperature and shear strain rate experienced by

214 the material between the centre of the WZ and the BM during the CDW. It is well

215 understood that the strain rate and temperature experienced by the material in the WZ

216 are relatively higher than that of the TMAZ [1]. Therefore, the temperature and the strain

217 energy in the WZ overcomes the threshold for recrystallisation, resulting in strain-induced

218 dynamic recrystallisation while some of the strain energy still exists in the microstructure

219 in form of dislocation cell structures manifested as LAGBs. In the HAZ (see Fig. 3g), the

220 grains were coarser than that of the $\mathrm{WZ}$ and TMAZ with an average grain size $\approx 10.5 \mu \mathrm{m}$,

221 which was similar to that of the BM $(11.2 \mu \mathrm{m})$. This small decrease in the grain size in the

$222 \mathrm{HAZ}$ is mainly because of the carbide precipitates that hinders the grain growth.

223 Moreover, the fraction of LAGBs and HAGBs were calculated as $\approx 55$ and $45 \%$,

224 respectively, which are similar to those of the BM (Fig. 3b and h).

\section{3.2. Tensile properties of the weld}

226 The flow behaviour of the tensile specimens, taken from different welding

227 conditions was investigated by conducting tensile tests at room temperature. The results

228 were then compared with that of the BM material. The engineering stress-strain curves

229 corresponding to different weld samples are shown in Fig. 4a where they all exhibit

230 discontinuous yielding (i.e., double yielding) and drastic strain hardening behaviour. This

231 phenomenon is shown in the inset of Fig. 4a in the form of two inflexion points and was

232 found to occur for all the tested specimens. The uniform and total elongation values 
Continuous drive friction welding of AISI 8630 low-alloy steel: experimental investigations on microstructure evolution and mechanical properties Journal of Manufacturing Science and Engineering

233 obtained from the stress-strain curves show that the maximum total elongations (TE)

234 were exhibited by the CD7 and CD9 weld conditions (see Fig. 4b) which corresponds to 235 the welds produced under the highest rotational speed (1200-1400 rpm). The occurrence

236 of necking followed by final fracture was noticed in a region between the HAZ and BM for

237 all the tested specimens, which is an indication of the higher strength of the weld zone.

238 The formation of Lüders bands that are associated with the formation of the Cottrell

239 atmosphere can be considered as the major reason for the yield point elongation (shown

240 in Fig. 4b). A Cottrell atmosphere is created by the diffusion of interstitial atoms, such as

241 carbon or nitrogen, leading to the obstruction of dislocations and is very likely to occur

242 during the welding process [14]. Significant strain hardening was observed in all

243 specimens irrespective of the welding condition until the ultimate tensile strength (UTS)

244 was reached. A uniform elongation (UE) of 4.7-6.6\% was recorded for these tests

245 whereas, the maximum elongation was that of the CD9 specimen. The fracture surface of

246 the tested specimens exhibited cup-cone failure which is an indication of ductile fracture.

247 The variation in the yield and UTS of the tested specimens is presented in Fig. 4c and d,

248 respectively. The maximum range of yield and UTS values were recorded for tensile

249 specimens extracted from the welds carried out at the highest rotational speeds (i.e. CD

250 7-9). The yield and UTS of the BM were $587 \mathrm{MPa}$ and $751 \mathrm{MPa}$, respectively. Thus, it can

251 be concluded that a significant increase in the yield strength was obtained for the welds

252 produced under the maximum rotational speeds, whereas the increase in the UTS was

253 marginal. Meanwhile, more than $100 \%$ joint efficiency (i.e. ratio of the strength of the

254 weld to that of the BM) was achieved for all weld conditions. The effects of other process 
Continuous drive friction welding of AISI 8630 low-alloy steel: experimental investigations on microstructure evolution and mechanical properties Journal of Manufacturing Science and Engineering

255 parameters (i.e. friction force, forge force and friction dwell time) have been discussed in

256 detail in the following sections.

\section{3.3. Strain hardening behaviour of the welds}

The strain hardening rate (SHR) was calculated from the plastic regime of the true

259 stress-strain curves and smoothened using the adjacent averaging method. The SHR

$260\left(\theta=\frac{d \sigma}{d \varepsilon}\right)$ of all the weld samples with respect to the true strain are shown in Fig. 5 . The

261 SHR of the welds were significantly higher than that of the BM. The welds exhibited three

262 stages of SHR (i.e. stage II, III and IV) as a function of true plastic strain. Stage-I is not

263 presented in Fig. 5 as it corresponds to the deformation of the welded materials in the

264 elastic regime. The strain hardening behaviour depends on the dislocation density and

265 grain size of the materials and has been explained by Khodaverdizadeh et al. [15] based

266 on dislocation theory. The authors reported that for friction stir welded copper material,

267 the coarsening of the grains resulted in a decrease in the SHR, whereas a drop in the 268 dislocation density leads to an increase in the SHR of the welds. As shown in Fig. 5, an

269 initial steep increase in the SHR was evaluated which corresponds to stage II that can be

270 linked to microstructural characteristics.

271 The initial steep increase in the SHR at lower strains can be attributed to (a) the

272 high dislocation density in the ferrite-martensite interfaces, (b) internal stress generation

273 in the weld due to the post-CDW rapid cooling from the austenitic region (i.e. at or above

$\left.274 A_{c_{3}}\right)$, and $(\mathrm{c})$ the difference in the flow behaviour of the constituent microstructural

275 phases (i.e., martensite, bainite and ferrite). Once the true plastic strain exceeds $\sim 0.2 \%$,

276 the curves exhibit a prompt decrease indicating the start of stage III work-hardening 
Continuous drive friction welding of AISI 8630 low-alloy steel: experimental investigations on microstructure evolution and mechanical properties Journal of Manufacturing Science and Engineering

277 behaviour. In this stage, dynamic recovery and dislocation annihilation occur as opposed

278 to dislocation multiplication. According to Ashrafi et al. [16], during tensile deformation,

279 a reduction in the work hardening rate of ferritic/bainitic/martensitic microstructures is

280 expected because their plastic deformation is restricted by the hard martensite phase. In

281 other words, martensite being the hardest phase will remain in the elastic state during

282 the initial stage of deformation, whereas, plastic flow will occur in the ferrite and bainite

283 matrix. Under such circumstances, the applied stress is transferred from the

284 ferrite/bainite to the martensite in the WZ and TMAZ. However, due to the change in the

285 content of the available phases in the $\mathrm{WZ}$ and TMAZ, the stress transfer is different and

286 thus leads to heterogeneous stress localisation [17]. In this study, as observed from the

287 microstructure (refer Fig. 4), no evidence of martensite is found in the HAZ and the BM,

288 leading to the conclusion, that both ferrite and bainite withstand the entire stress and

289 undergo deformation during the initial stages of deformation. In the WZ and TMAZ,

290 martensite is also observed in addition to ferrite and bainite. This implies that the stresses

291 accumulated in the ferrite and bainite were transferred to martensite, and at a later stage,

292 all these three phases undergo plastic deformation. For this investigation, it can be

293 concluded that stage III marks the simultaneous deformation of all the available phases

294 i.e. ferrite, bainite and martensite, which is also governed by dynamic recovery and cross-

295 slip processes [18]. Similar observations for simultaneous deformation of both ferrite and

296 martensite in stage III have been documented in other reports [18-20]. Following stage

297 III, stage IV indicates a progressive decrease in strain hardening rate as a function of true

298 strain. According to Cuddy et al. [21], the increase in the dislocation movements due to 
Continuous drive friction welding of AISI 8630 low-alloy steel: experimental investigations on microstructure evolution and mechanical properties Journal of Manufacturing Science and Engineering

299 the cross-slip phenomenon can be considered as the major reason for this relatively linear

300 decline in the strain hardening. The microstructures of all the weld regions (i.e. WZ, TMAZ,

301 and HAZ) and BM depicted different contents for different phases. Thus, it is expected

302 that during the deformation process, some of the phases undergo elastic deformation,

303 while other phases experience plastic deformation. This heterogeneity in the deformation

304 behaviour combined with the different yield strengths associated with the constituent

305 phases may be the cause of the observed fluctuations in the SHR curves.

306 The strain hardening exponent was evaluated to further investigate the strain

307 hardening behaviour of the welds. The strain hardening exponent is a measure of the

308 strain hardenability; typically a material with a high strain hardening exponent undergoes

309 uniform deformation in the plastic regime. The stress-strain behaviour in the plastic

310 regime during the uniform deformation stage is expressed by the Hollomon relationship

311 in Equation 2 [22].

$$
\sigma=k \varepsilon^{n}
$$

313 In Equation 2, $k$ is the coefficient of strength and $n$ is the strain hardening

314 coefficient, $\sigma$ and $\varepsilon$ represent the true stress and true strain, respectively. The weld

315 specimens exhibited a non-linear variation in the $\ln \sigma$ versus $\ln \varepsilon$, thus demonstrating a

316 bi-linear slope in the strain hardening (see Fig. 6a) behaviour. An illustrative example of

317 the methodology followed for evaluating the $n_{1}$ and $n_{2}$ exponents (i.e., for both strain

318 hardening stages) is presented in Fig. 6b. The linear equations for the fitted curves and

319 the degree of fit (i.e. $R^{2}$ ) were considered when evaluating the strain hardening exponents

320 presented in Table 2. The first stage of the strain hardening curve depicts a higher strain 
Continuous drive friction welding of AISI 8630 low-alloy steel: experimental investigations on microstructure evolution and mechanical properties Journal of Manufacturing Science and Engineering

321 hardening exponent value $\left(n_{1}\right)$ compared to the second stage $\left(n_{2}\right)$. The different stages of

322 strain hardening behaviour of the weld tensile test specimens can be explained based on

323 the level of plastic deformation experienced by the constituent microstructural phases.

324 As martensite is harder than ferrite, bainite and austenite, during the onset of plastic

325 deformation, the regions dominated by ferrite and bainite phases will undergo initial

326 deformation until the threshold stress is reached, after which the plastic deformation

327 extends to martensite. The observed dual-slope in the strain hardening behaviour of the

328 weld specimens can be attributed to this heterogeneous plastic deformation behaviour

329 in these phases. The first stage of strain hardening, indicates the deformation of softer

330 phases such as austenite and ferrite, whereas, the second stage demonstrates the plastic

331 deformation in the bainite and martensite in addition to austenite and ferrite. These

332 observations are in an agreement with previous results reported on the strain hardening 333 behaviours of different types of dual-phase steels [23,24]. Higher values of $n_{1}$ compared

334 to $n_{2}$ were evaluated for all the welds, which based on Ashby's [25] explanations, is due 335 to the pile-up of the geometrically necessary dislocations at the interfaces of the phases.

336 Moreover, the strain hardening exponents of all the welds were found to be lower than

337 those obtained for the BM. This implies a decrease in the deformability of the weld 338 specimens in the uniform plastic regime compared to the BM. This can be attributed to 339 the presence of martensite in the WZ and TMAZ of the welded specimens, which 340 ultimately leads to an increase in the strength of the weld specimens at the loss of 341 ductility. The decrease in the $n$ values indicates similar behaviour i.e. a drop in the ductility 342 of the weld specimens compared to the BM. 
Continuous drive friction welding of AISI 8630 low-alloy steel: experimental investigations on microstructure evolution and mechanical properties Journal of Manufacturing Science and Engineering

The hardening behaviour of the welds was also evaluated by the hardening

344 capacity $\left(H_{c}\right)$ based on an approach described by Afrin et al. [26] using a normalised

345 relationship expressed in Equation 3.

$$
H c=\frac{\sigma_{u}}{\sigma_{y}}-1
$$

347 In Equation 3, $\sigma_{\mathrm{u}}$ and $\sigma_{\mathrm{y}}$ represent the UTS and yield strength of the material. The

348 evaluated hardening capacity values for the welds and BM are provided in Table 2. The

349 data shows a decrease in the hardening capacity of the welded specimens compared to

350 the BM. As per Equation 2, the yield strength of a material has a substantial effect on its

351 hardening capacity, which is linked to the grain size based on the Hall-Petch relationship.

352 Hardening in the WZ and TMAZ, owing to the austenite to martensite phase

353 transformation under rapid cooling results in a significant increase in the yield strength.

354 This can be considered as a reason for the observed drop in the hardening capacity of the 355 welds.

\section{3.4. Hardness distribution in the weld}

357 The 2D microhardness contour maps of all nine welds are presented in Fig. 7. A

358 significant variation in the hardness profiles across the transverse cross-section of the

359 weld specimens was observed, regardless of the welding condition. The average hardness

360 in the WZ of the welds was measured to be in the range of $500-660 \mathrm{HV}$, and that of the

361 TMAZ was between 290-500 HV. A few spots in the WZ with significantly higher hardness

362 values were noticed in all welds. The maximum hardness values measured in the WZ of

363 all welds, which in turn, is the hardest zone for each condition, are presented in Table 3.

364 Overall, the highest hardness in the WZ was that of the CD6 weld ( 716 HV), and the 
Continuous drive friction welding of AISI 8630 low-alloy steel: experimental investigations on microstructure evolution and mechanical properties Journal of Manufacturing Science and Engineering

365 lowest value was that of the CD8 weld ( $661 \mathrm{HV})$. Note that the lowest hardness values

366 in the WZ were measured for the weld carried out under the highest rotational speed.

367 The variation in the hardness profile of the HAZ was in-between $~ 230-285 \mathrm{HV}$, which is

368 not significantly different from that of the BM ( 220-230 HV). The WZ demonstrated

369 nearly a threefold increase in the hardness compared to the BM. This substantial upsurge

370 is due to the formation of predominant lath martensite in the WZ. Similar explanations

371 can be provided for the TMAZ where due to the lower martensite content and increased

372 bainite and ferrite fractions, the hardness was comparatively lower than the WZ,

373 meanwhile much higher than that of the BM. Although the variation in hardness profile

374 across the WZ and TMAZ was extensive, no evidence of macro or microcracks were

375 observed by the techniques (i.e., OM and SEM) used in this study.

376 3.5. Effect of process parameters on the mechanical properties of the welds

377 The variation in the process parameters applied during CDW (i.e., rotational

378 speed, friction and forge forces) play an important role in altering the mechanical

379 properties (e.g., UTS) of the welds. To evaluate the contribution of each one of these

380 process parameters, an analysis of variance (ANOVA) was carried out as per the standard

381 ANOVA procedure [27]. In this analysis, the F-variable that specifies the confidence level

382 of process parameters, and the $\mathrm{P}$-variable that indicates the fraction of the total variance

383 of an individual parameter, were used. The signal to noise $(\mathrm{S} / \mathrm{N})$ ratio along with the $\mathrm{F}$ and

$384 \quad \mathrm{P}$ variables considering the UTS as a response parameter were calculated to identify the

385 individual effects of the process parameters. The $\mathrm{S} / \mathrm{N}$ ratio for different process

386 parameters is presented in Fig. 8, and a summary of the calculated values are presented 
Continuous drive friction welding of AISI 8630 low-alloy steel: experimental investigations on microstructure evolution and mechanical properties Journal of Manufacturing Science and Engineering

387 in Table 4. As evident, the friction force and rotational speed had substantial impacts on

388 the UTS due to the larger F-ratio. However, the rotational speed was concluded as the

389 predominant process parameter due to its highest contribution ( $60 \%)$ in increasing the

390 tensile UTS. Conversely, the forge force had a negligible effect on the variation in UTS of

391 the welds. Thus, it can be concluded that an increase in the rotational speed results in a

392 higher UTS, whereas increasing the friction force above a nominal value of $325-375 \mathrm{kN}$,

393 drops the UTS significantly.

394 The weld produced under the CD9 condition (see Table 1) exhibited the highest

395 yield strength ( $626 \mathrm{MPa})$, UTS ( 755 MPa) and static toughness ( 137.5 J/mm3). Also,

396 the CD9 weld exhibited the lowest hardness, which is preferred, among all the welds

397 except CD8. Thus, based on the measured mechanical properties, CD9 which was

398 produced under the highest rotational speed and friction force, and the lowest forge force

399 is considered to be the optimum weld condition.

400 3.6. Fracture surface examination

401 The analysis of the fracture surfaces is beneficial for understanding the effect of

402 process parameters on the weld joints and further classifying the fracture mechanisms.

403 Since the rotational speed was the most critical parameter affecting the mechanical

404 strength of the weld joints, the fracture surfaces of the tensile specimens corresponding

405 to the three different rotational speeds were examined and the results are presented in

406 Fig. 9. It is worth mentioning here that the term "weld joint" indicates the presence of all

407 the different regions i.e. WZ, TMAZ, HAZ and the BM. The microstructural features

408 observed on the fracture surface of the CD2 weld condition is shown in Fig. 9a-c. The SEM 
Continuous drive friction welding of AISI 8630 low-alloy steel: experimental investigations on microstructure evolution and mechanical properties Journal of Manufacturing Science and Engineering

409

macrograph showed in Fig. 9a as an inset exhibits a typical cup and cone fracture surface

410 indicating a ductile mode of failure. The cup and cone fracture indicates that the applied

411 stress during the uniaxial tensile test is not aligned with the principal stress in the sample,

412 and this leads to maximised shear stress. The SEM images in Fig. 9a-c show the presence

413 of dimples, voids along with a few micro-cracks, and spherical particles. According to Yu

414 et al. [28], the spherical particles are formed due to the fracture of the brittle precipitates

415 and thus are an indication of a brittle failure. The presence of these features on the

416 fracture surface is an indication of mixed mode (i.e. ductile - "local" brittle) failure [28].

417 The fracture surface of the tensile specimen made from CD6 and CD9 welds exhibited

418 similar features and the presence of dimples and voids, as well as brittle spherical

419 particles (refer Fig. 9d-i).

420 To further understand the correlation between the dimples and the exhibited

421 ductility of the weld parts, the morphology of the dimples was assessed in terms of their

422 average size and density. These were measured for CD2, CD6 and CD9 weld joints,

423 produced under different rotational speeds during CDW (Table 1 ), and the results are

424 shown in Fig. 10. The density of dimples appears to increase with an increased rotational

425 speed. The dimple density for the CD2, CD6 and CD9 welds were calculated to be $~ 2.9 \pm$

$4260.3,3.0 \pm 0.3$ and $3.2 \pm 0.2 / \mu \mathrm{m}^{2}$, respectively. The average dimple size was found to

427 decrease with increasing rotational speed for CD2 and CD6 weld conditions, however, a

428 negligible difference is observed with a further increase in the rotational speed from CD6

429 to CD9. The average dimple size was measured to be $\sim 0.76 \pm 0.1,0.58 \pm 0.1$ and $0.59 \pm$

$4300.1 \mu \mathrm{m}$, respectively for the CD2, CD6 and CD9 welds. Overall, an increase in the dimple 
Continuous drive friction welding of AISI 8630 low-alloy steel: experimental investigations on microstructure evolution and mechanical properties Journal of Manufacturing Science and Engineering

431 density is an indication of the increase in the ductility of the material [20]. This is in

432 agreement with the outcome observed for the CD9 weld condition, which exhibited the

433 highest dimple density resulting in the highest ductility among all the examined welds.

\section{4. CONCLUSIONS}

435 In this paper, the CDW of modified AISI-8630 steel using different weld parameters

436 was investigated. The mechanical properties were evaluated and the concomitant

437 changes in the microstructural features were correlated with the mechanical properties.

438 The key findings of this study are summarised as the following:

439 1. The microstructure of the WZ displayed the presence of predominant martensite along

440 with bainite and traces of retained austenite, whereas in the TMAZ the existence of

441 bainite, ferrite, martensite and carbide precipitates were noticed. These features were

442 correlated with the conceivable experienced temperature across the different regions of

443 the weld. It was concluded that the WZ experienced a temperature closer to the $A_{3}$ and

444 the TMAZ in between $A c_{1}$ and $A c_{3}$.

445 2. The EBSD orientation maps of the welds demonstrated a gradual increase in the grain

446 size from the centre of WZ towards the HAZ. Though the microstructures of all the weld

447 regions were dominated by LAGBs, with higher fractions in the WZ and TMAZ, a slightly

448 smaller fraction of LAGBs and considerably smaller grain size was measured for the WZ

449 compared to the TMAZ. These were attributed to the variation in the level of shear strain

450 and temperature between these zones during the welding process.

451 3. The welds demonstrated discontinuous yielding and three stages of strain hardening

452 rate during tensile loading. An increase in the yield strength and UTS of all welds was 
Continuous drive friction welding of AISI 8630 low-alloy steel: experimental investigations on microstructure evolution and mechanical properties Journal of Manufacturing Science and Engineering

453 observed at the expense of a drop in ductility, compared to those of the BM. The welds

454 exhibited a substantial decline in the hardening capacity and a significant upsurge in the

455 hardness compared to the BM.

456 4. Based on the investigated mechanical properties, the weld produced under the highest

457 rotational speed (1200 - $1400 \mathrm{rpm})$, highest friction force (375 - $425 \mathrm{kN})$, and an

458 intermediate forge force $(600-650 \mathrm{kN})$ resulted in the desired mechanical properties and

459 as such these parameters were considered as the optimum welding condition. The

460 rotational speed followed by friction force were concluded to be the most important

461 parameters affecting the mechanical properties of the welds. The forge force had a

462 negligible effect on the strength of the weld.

\section{ACKNOWLEDGMENT}

464 The authors acknowledge the Advanced Forming Research Centre (AFRC) at the

465 University of Strathclyde for providing the laboratory facilities, which receives partial

466 financial support from the UK's High-Value Manufacturing CATAPULT. The authors would

467 like to acknowledge Kornelia Kondziolka for preparing the metallurgical specimens and

468 Jacqueline Schramm for her help with the mechanical testing.

\section{FUNDING}

470 This project received funding from the Tier-I members of the Advanced Forming Research

471 Centre (AFRC) and UK's High-Value Manufacturing CATAPULT.

472 


\section{REFERENCES}

474 [1] A. Banerjee, M. Ntovas, L. Da Silva, S. Rahimi, Effect of rotational speed and inertia on 475 the mechanical properties and microstructural evolution during inertia friction welding of $4768630 \mathrm{M}$ steel, Materials Letters 296 (2021) 129906.

477 [2] S.K. Sharma, S. Maheshwari, A review on welding of high strength oil and gas pipeline steels, Journal of Natural Gas Science and Engineering 38 (2017) 203-217.

479 [3] S.T. Selvamani, K. Palanikumar, K. Umanath, D. Jayaperumal, Analysis of friction welding parameters on the mechanical metallurgical and chemical properties of AISI 1035 steel joints, Materials \& Design (1980-2015) 65 (2015) 652-661. [4] W. Li, A. Vairis, M. Preuss, T. Ma, Linear and rotary friction welding review, International Materials Reviews 61(2) (2016) 71-100. mechanical and metallurgical properties of super duplex stainless steel joints using friction welding process, Journal of Manufacturing Processes 15(4) (2013) 558-571. [6] M. Hazra, K.S. Rao, G.M. Reddy, Friction welding of a nickel free high nitrogen steel: influence of forge force on microstructure, mechanical properties and pitting corrosion resistance, Journal of Materials Research and Technology 3(1) (2014) 90-100. 304) joined by friction welding, Materials \& Design 28(7) (2007) 2244-2250. welded dissimilar joints of aluminum alloys, Materials Letters 231 (2018) 68-71. [10] Standard Test Methods for Tension Testing of Metallic Materials [Metric]. Crystallographic Texture in a Double-Sided Friction Stir Welded Microalloyed Steel, Metallurgical and Materials Transactions A 48(1) (2017) 362-378. Materials Transactions A 50(6) (2019) 2748-2764. solution strengthened Ni-based superalloy: Microstructure evolution and mechanical properties studies, Journal of Manufacturing Processes 34 (2018) 442-450. keyhole plasma arc welded dual phase steel DP600, Journal of Materials Processing Technology 270 (2019) 28-36.

513 [16] H. Ashrafi, M. Shamanian, R. Emadi, N. Saeidi, Microstructure, Tensile Properties and 514 Work Hardening Behavior of GTA-Welded Dual-Phase Steels, Journal of Materials 515 Engineering and Performance 26(3) (2017) 1414-1423. 
Continuous drive friction welding of AISI 8630 low-alloy steel: experimental investigations on microstructure evolution and mechanical properties Journal of Manufacturing Science and Engineering

516 [17] Q.-h. Pang, Z.-z. Zhao, D. Tang, Microstructure and properties of hot-rolled high strength bainitic steel by laser welding, Materials \& Design 87 (2015) 363-369.

518 [18] T.S. Byun, I.S. Kim, Tensile properties and inhomogeneous deformation of ferrite519 martensite dual-phase steels, Journal of Materials Science 28(11) (1993) 2923-2932.

520 [19] A. Bag, K.K. Ray, E.S. Dwarakadasa, Influence of martensite content and morphology 521 on tensile and impact properties of high-martensite dual-phase steels, Metallurgical and 522 Materials Transactions A 30(5) (1999) 1193-1202.

523 [20] A. Banerjee, H. Wang, A. Brown, A. Ameri, Q. Zhu, S. Bhattacharyya, P.J. Hazell, B.G. 524 Prusty, Experimental investigation on the dynamic flow behaviour and structure-property 525 correlation of dual-phase high carbon steel at elevated temperatures, Materials Science 526 and Engineering: A 771 (2020) 138655.

527 [21] J. Cuddy, M. Nabil Bassim, Study of dislocation cell structures from uniaxial 528 deformation of AISI 4340 steel, Materials Science and Engineering: A 113 (1989) 421-429. 529 [22] J.H. Hollomon, Tensile deformation, Transactions of the Metallurgical Society of AIME $530162(1945)$ 268-289.

531 [23] M.M. Karimi, S. Kheirandish, Comparison of Work Hardening Behaviour of Ferritic532 Bainitic and Ferritic-Martensitic Dual Phase Steels, 80(2) (2009) 160-164.

533 [24] M.R. Akbarpour, A. Ekrami, Effect of ferrite volume fraction on work hardening 534 behavior of high bainite dual phase (DP) steels, Materials Science and Engineering: $A$ 535 477(1) (2008) 306-310.

536 [25] M.F. Ashby, The deformation of plastically non-homogeneous materials, The 537 Philosophical Magazine: A Journal of Theoretical Experimental and Applied Physics 538 21(170) (1970) 399-424.

539 [26] N. Afrin, D.L. Chen, X. Cao, M. Jahazi, Strain hardening behavior of a friction stir 540 welded magnesium alloy, Scripta Materialia 57(11) (2007) 1004-1007.

541 [27] P.J. Ross, Taguchi techniques for quality engineering: loss function, orthogonal 542 experiments, parameter and tolerance design, McGraw-Hill1988.

543 [28] H. Yu, Y. Wang, Fracture performance of high strength steels, aluminium and 544 magnesium alloys during plastic deformation, MATEC Web of Conferences 21 (2015) 54507001. 
Continuous drive friction welding of AISI 8630 low-alloy steel: experimental investigations on microstructure evolution and mechanical properties Journal of Manufacturing Science and Engineering

Fig. 1

Fig. 2

Fig. 3

Fig. 4

Fig. 5

Fig. 6
A CDW joint of the cylindrical tubes exhibiting rotating side, fixed side and the flash formation (not to scale). The $A D, R D$ and TD refers axial, radial and transverse direction, respectively.

SEM and OM micrographs of the BM and different regions of the weld (a) macro of the weld joint, (b) BM revealing the presence of different morphology of bainite, ferrite (F) and carbide precipitates; (c) and (d) OM and SEM micrographs of the WZ displaying the presence of bainitic ferrite $(B F)$, martensite (M) and retained austenite (RA); (e) SEM micrograph of the TMAZ exhibiting the presence of ferrite (F), martensite $(M)$, bainite $(B)$, and (f) HAZ exhibiting similar microstructure as that of BM i.e. presence of bainite, ferrite and carbides.

OIMs with IPF colouring with respect to the $A D$, and plots of misorientation angle distribution for different regions of the CD9 weld, (a) $B M,(b) W Z$, (c) TMAZ and (d) HAZ. The RD, AD and TD represents the radial, axial and transverse directions.

Fig. 4. (a) Engineering stress-strain curves for the welded materials and the magnified image in the inset showing the double yielding and yield point elongation during tensile tests for all samples, (b) uniform and total elongation, (c) and (d) show the variation in yield and UTS, respectively, as a function of rotation speed for different weld conditions.

The strain hardening rate versus true plastic strain of the welded samples exhibiting three different stages. Inset is the magnified plot exhibiting stage II.

(a) Strain hardening behaviour of the welds exhibiting variations of In $\sigma$ vs $\ln \varepsilon$, (b) methodology used for evaluating the strain-hardening exponents for CD 9 weld. 
Fig. 7 Microhardness maps of all the nine CDW welds exhibiting the hardness distribution across the WZ, TMAZ, HAZ and BM.

Fig. $8 \quad$ (a) ANOVA analysis exhibiting the effects of individual process parameters on the UTS of the welds performed in this study.

Fig. 9 Fracture morphologies of the welds following tensile experiments, (a)-(c) CD2 weld, (d)-(f) CD6 weld, (g)-(i) CD9 weld exhibiting the presence of various features such as dimples, micro-dimples, presence of spherical particles and macroscopic cracks.

Fig. 10 Variation in the measured dimple size and density as a function of weld conditions. 


\section{Table Caption List}

Table $1 \quad$ The identity and ranges of RFW process parameters implemented during CDW in this study.

Table 2 Strain hardening exponents and hardening capacity for the BM and the welds.

Table 3 Maximum hardness values obtained for the WZ of all the welds produced under different conditions.

Table 4 Summary of the calculated values for the ANOVA parameters. 


\section{Figures}

\section{Figures}

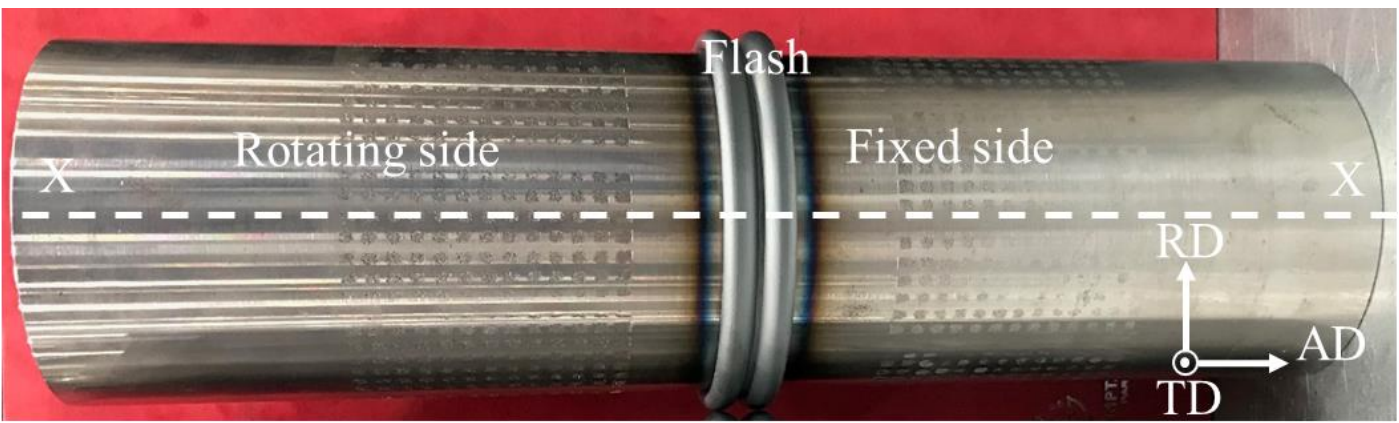

Fig. 1. A CDW joint of the cylindrical tubes exhibiting rotating side, fixed side and the flash formation (not to scale). The AD, RD and TD refers axial, radial and transverse directions, respectively. 

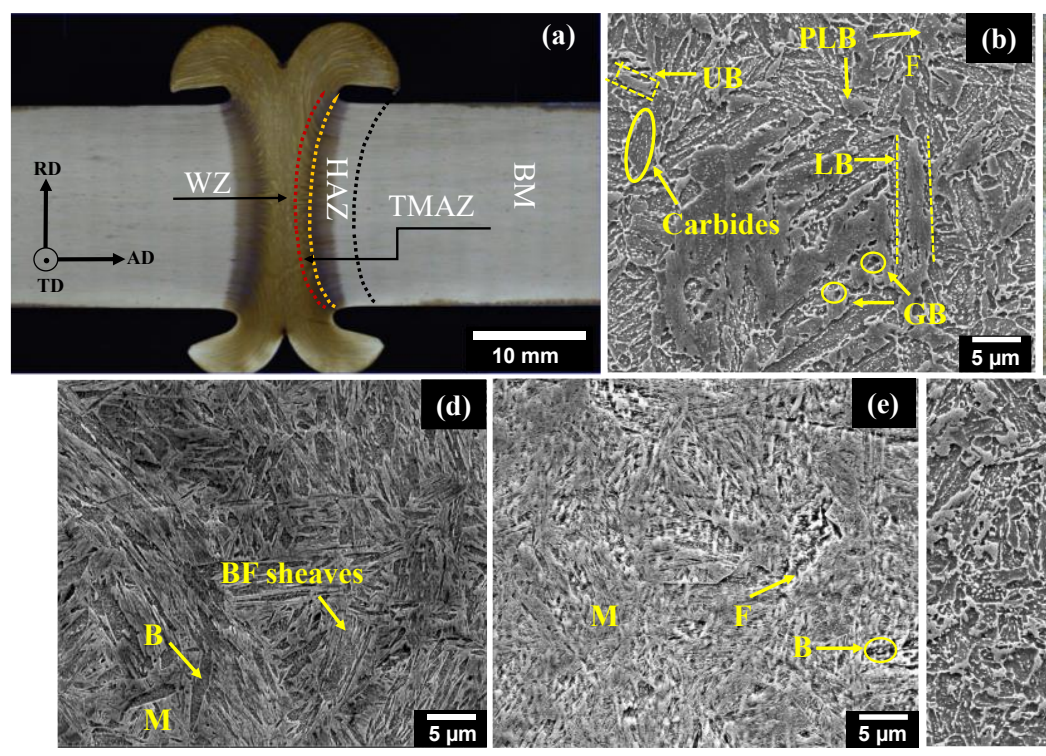
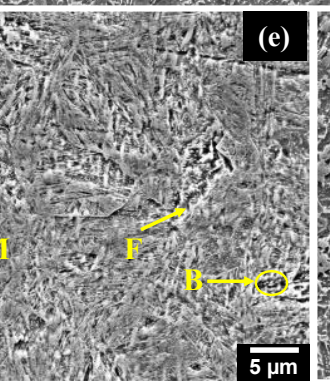

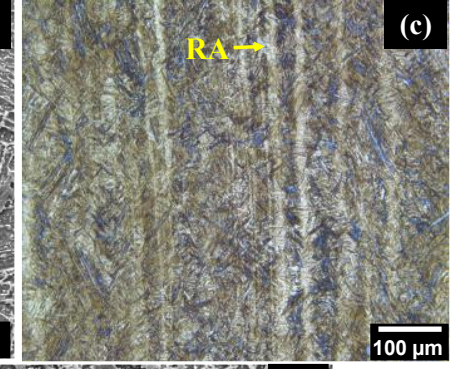

(f)

Fig. 2. SEM and OM micrographs of the BM and different regions of the weld (a) macro of the weld joint, (b) BM revealing the presence of different morphology of bainite, ferrite (F) and carbide precipitates; (c) and (d) OM and SEM micrographs of the WZ displaying the presence of bainitic ferrite $(B F)$, martensite $(M)$ and retained austenite (RA); (e) SEM micrograph of the TMAZ exhibiting the presence of ferrite (F), martensite $(M)$, bainite (B), and (f) HAZ exhibiting similar microstructure as that of BM i.e. presence of bainite, ferrite and carbides. 

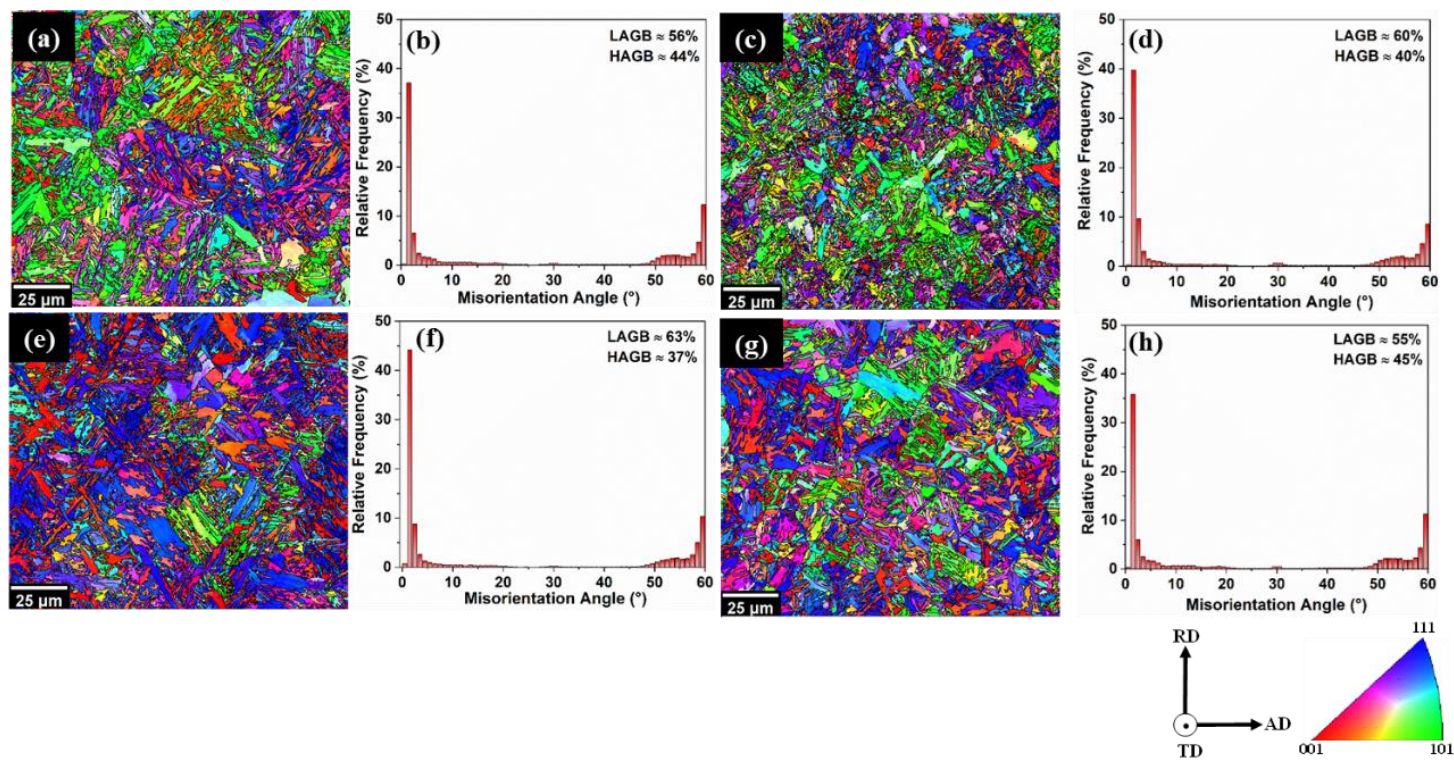

Fig. 3. OIMs with IPF colouring with respect to the $A D$, and plots of misorientation angle distribution for different regions of the CD9 weld, (a) BM, (b) WZ, (c) TMAZ and (d) HAZ. The RD, AD and TD represents the radial, axial and transverse directions. 

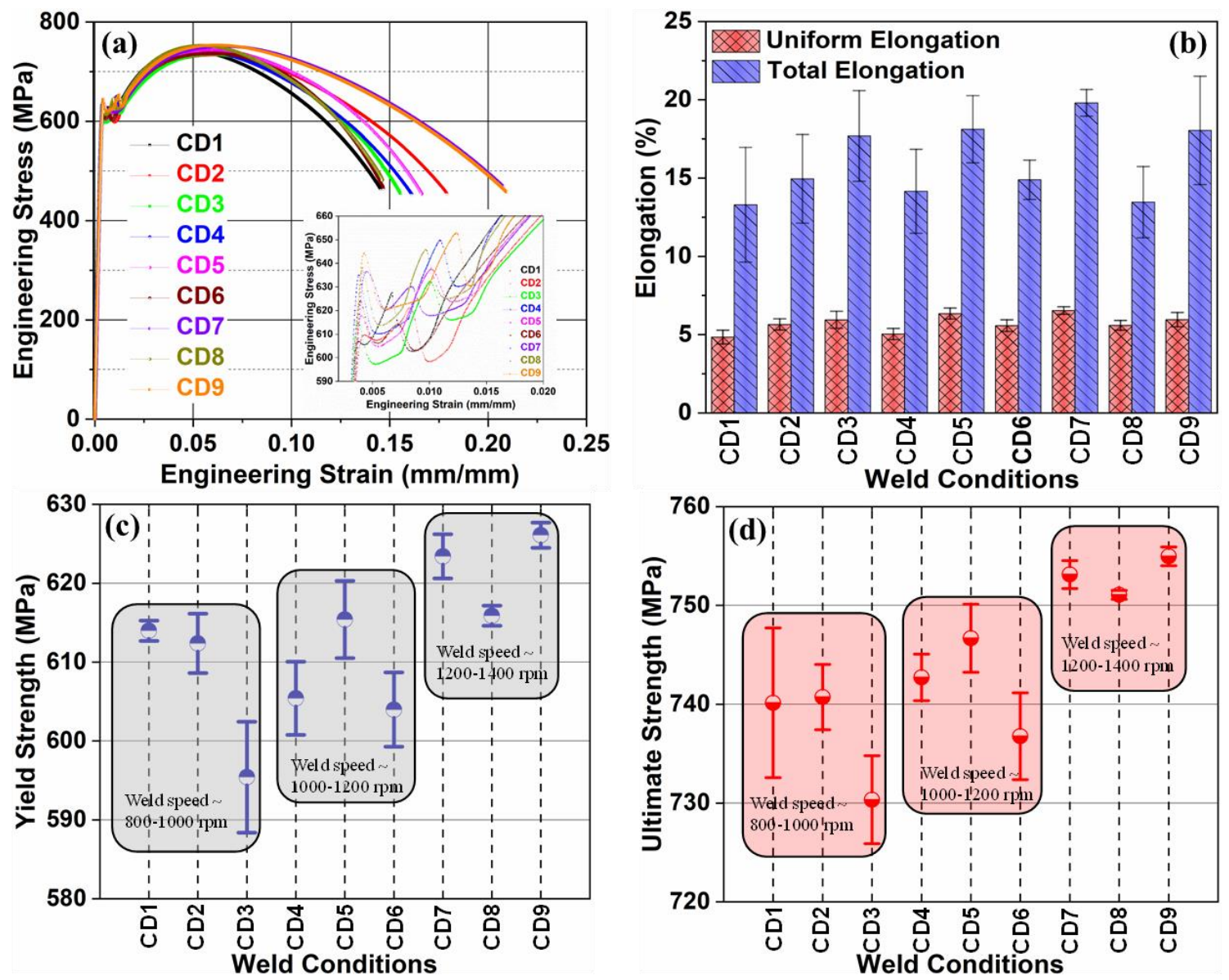

Fig. 4. (a) Engineering stress-strain curves for the welded materials and the magnified 558 image in the inset showing the double yielding and yield point elongation during tensile 559 tests for all samples, (b) uniform and total elongation, (c) and (d) show the variation in 560 yield and UTS, respectively, as a function of rotation speed for different weld conditions. 
561

562

563

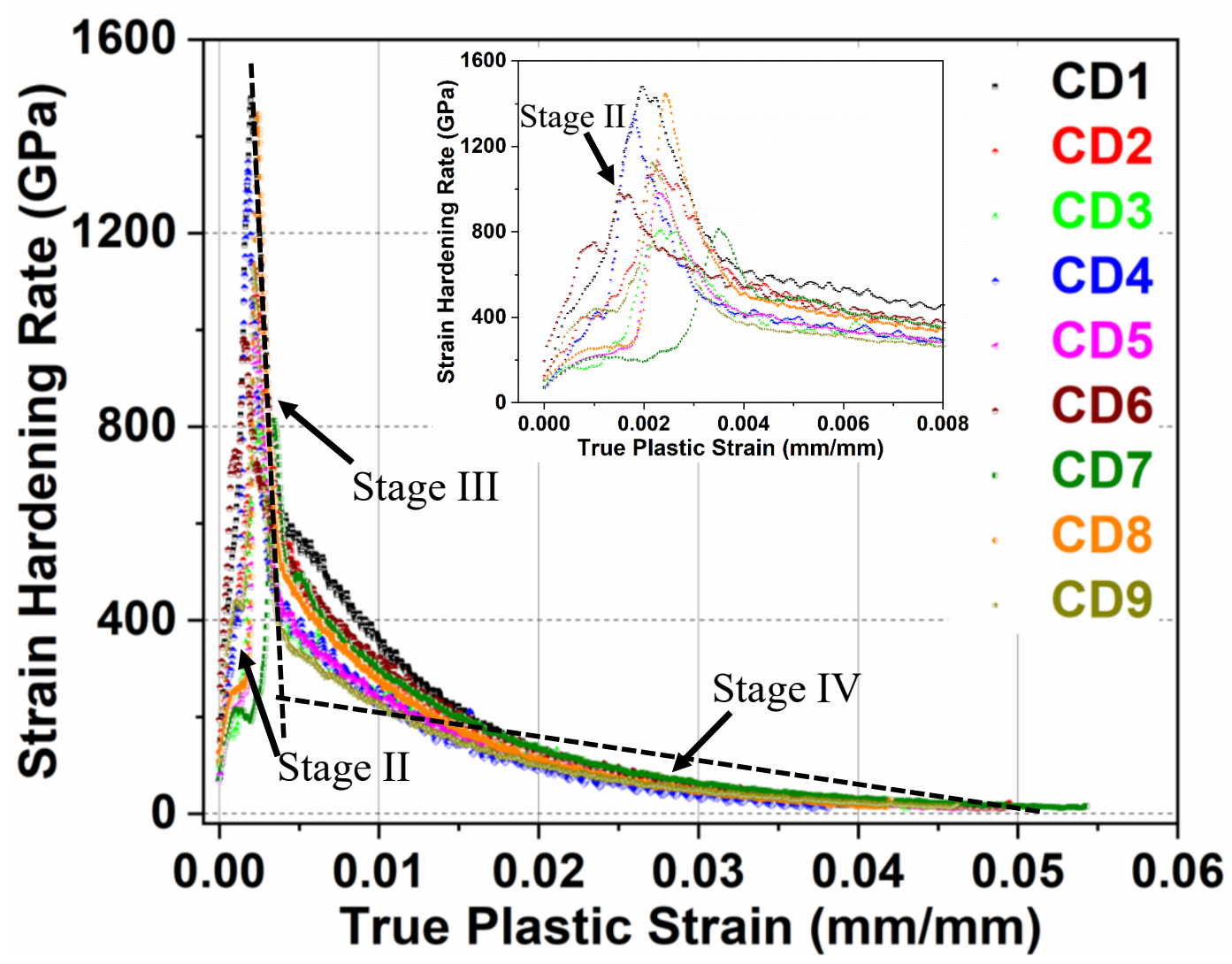

Fig. 5. The strain hardening rate versus true plastic strain of the welded samples exhibiting three different stages. Inset is the magnified plot exhibiting stage II. 

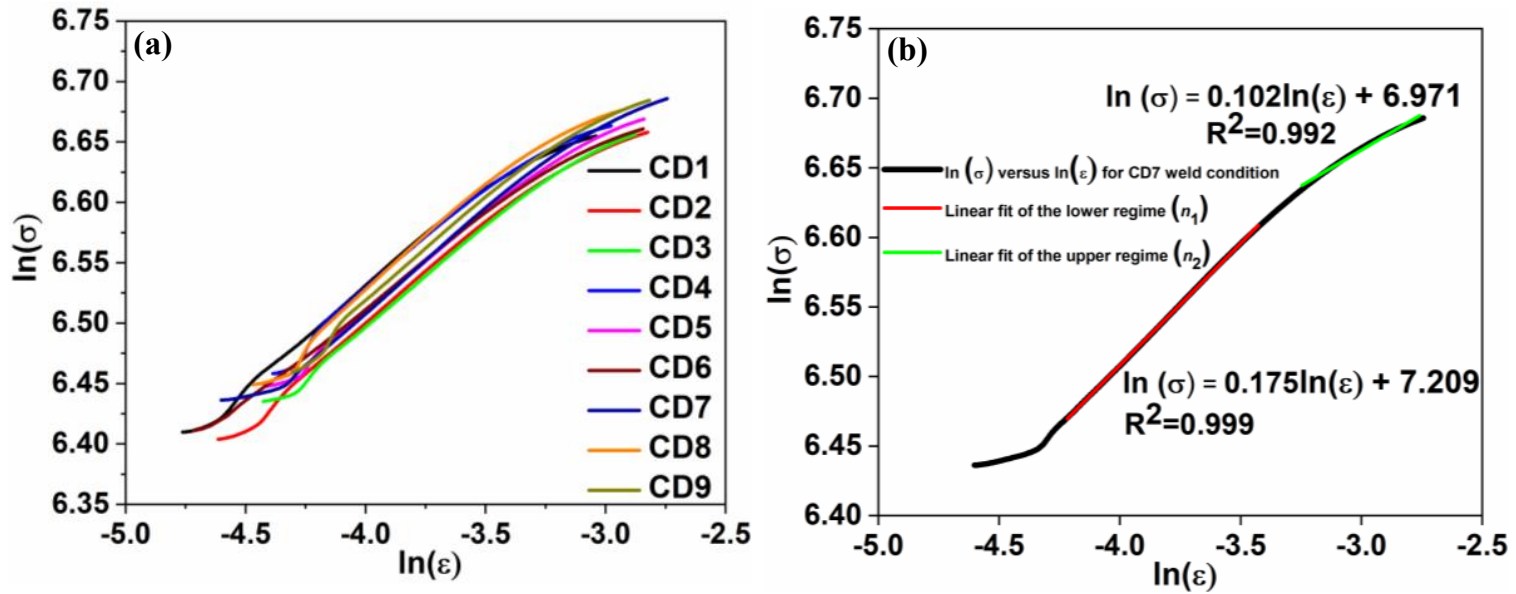

564

565

566
Fig. 6. (a) Strain hardening behaviour of the welds exhibiting variations of $\ln \sigma$ vs $\ln \varepsilon$, (b) methodology used for evaluating the strain-hardening exponents for CD 9 weld 

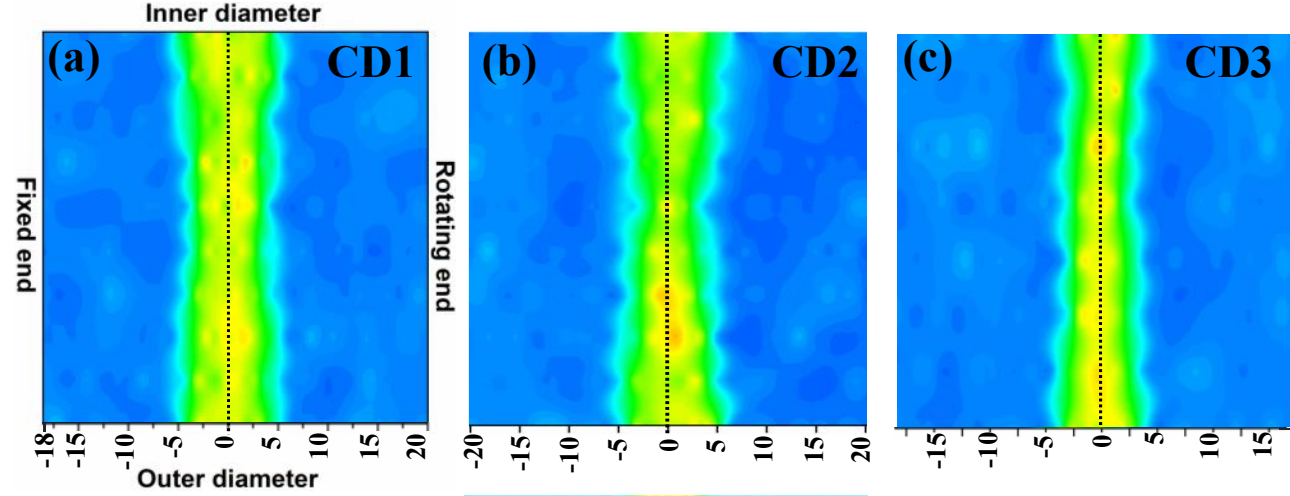

\section{$0.2 \mathrm{HV}$}
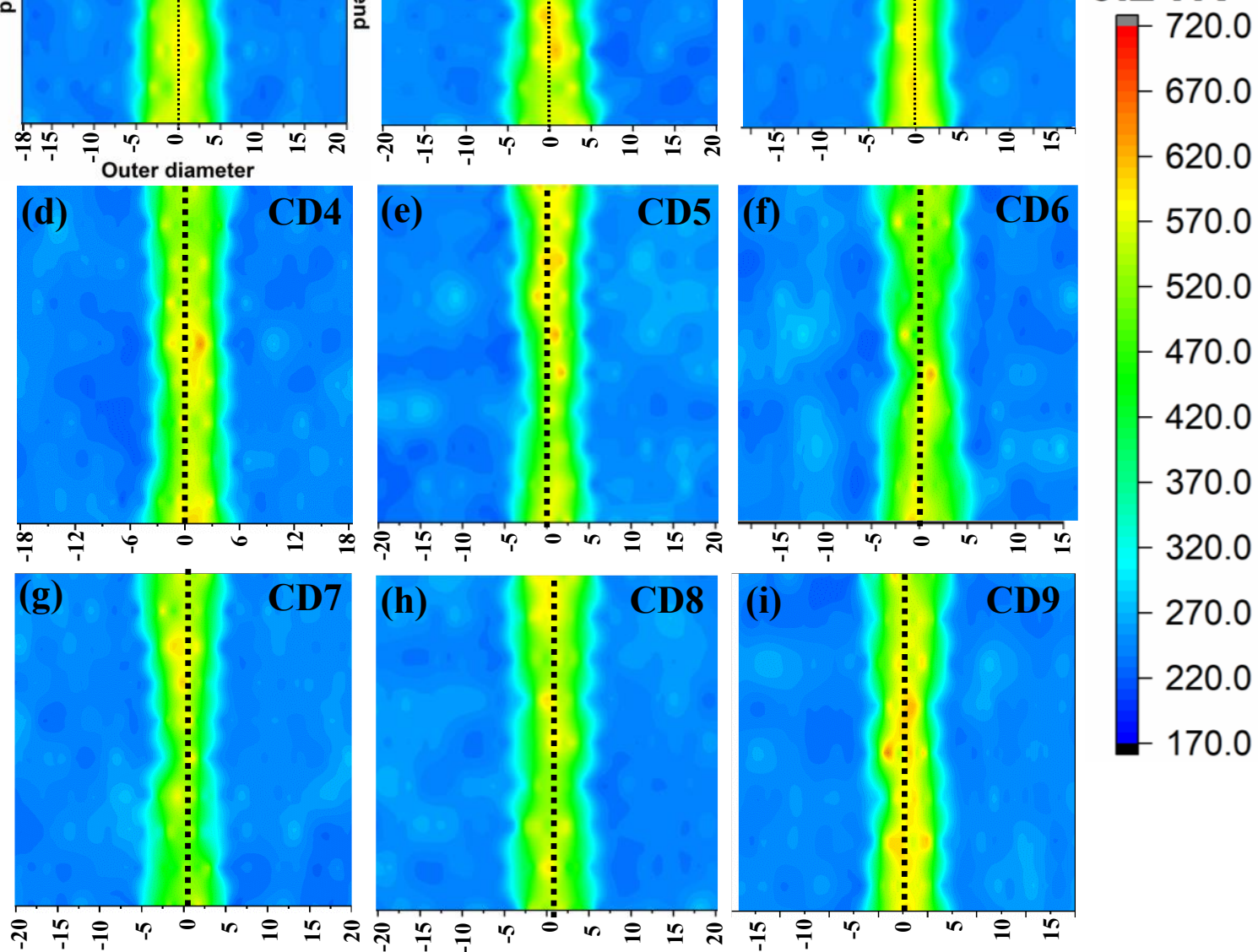

170.0

Fig. 7. Microhardness maps of all the nine CDW welds exhibiting the hardness distribution 570 across the $W Z, T M A Z, H A Z$ and $B M$. 


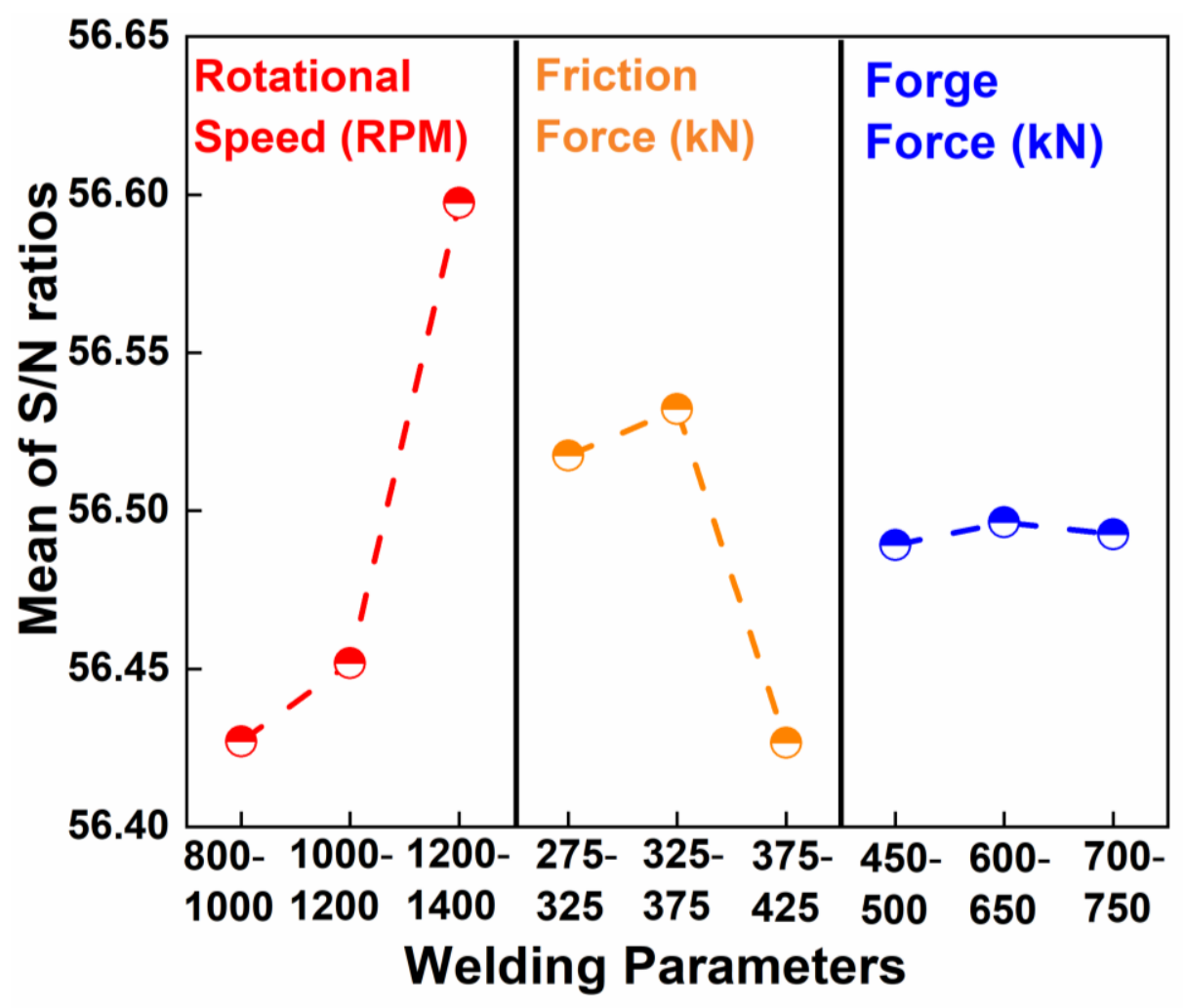

572 Fig. 8. ANOVA analysis exhibiting the effects of individual process parameters on the UTS 573 of the welds performed in this study. 

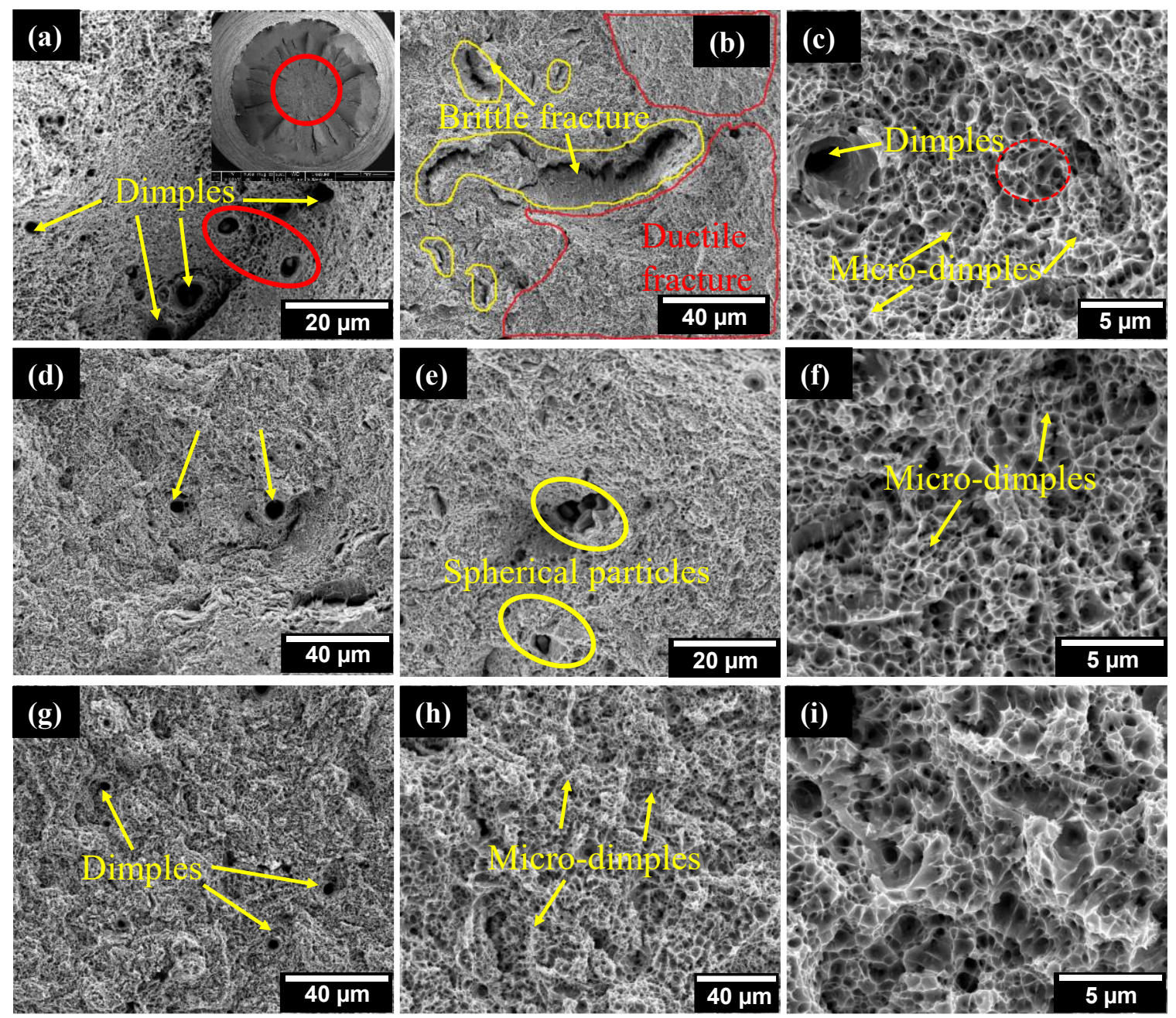

575 Fig. 9. Fracture morphologies of the welds following tensile experiments, (a) - (c) CD2

576 weld, (d) - (f) CD6 weld, (g) - (i) CD9 weld exhibiting the presence of various features such 577 as dimples, micro-dimples, presence of spherical particles and macroscopic cracks. 


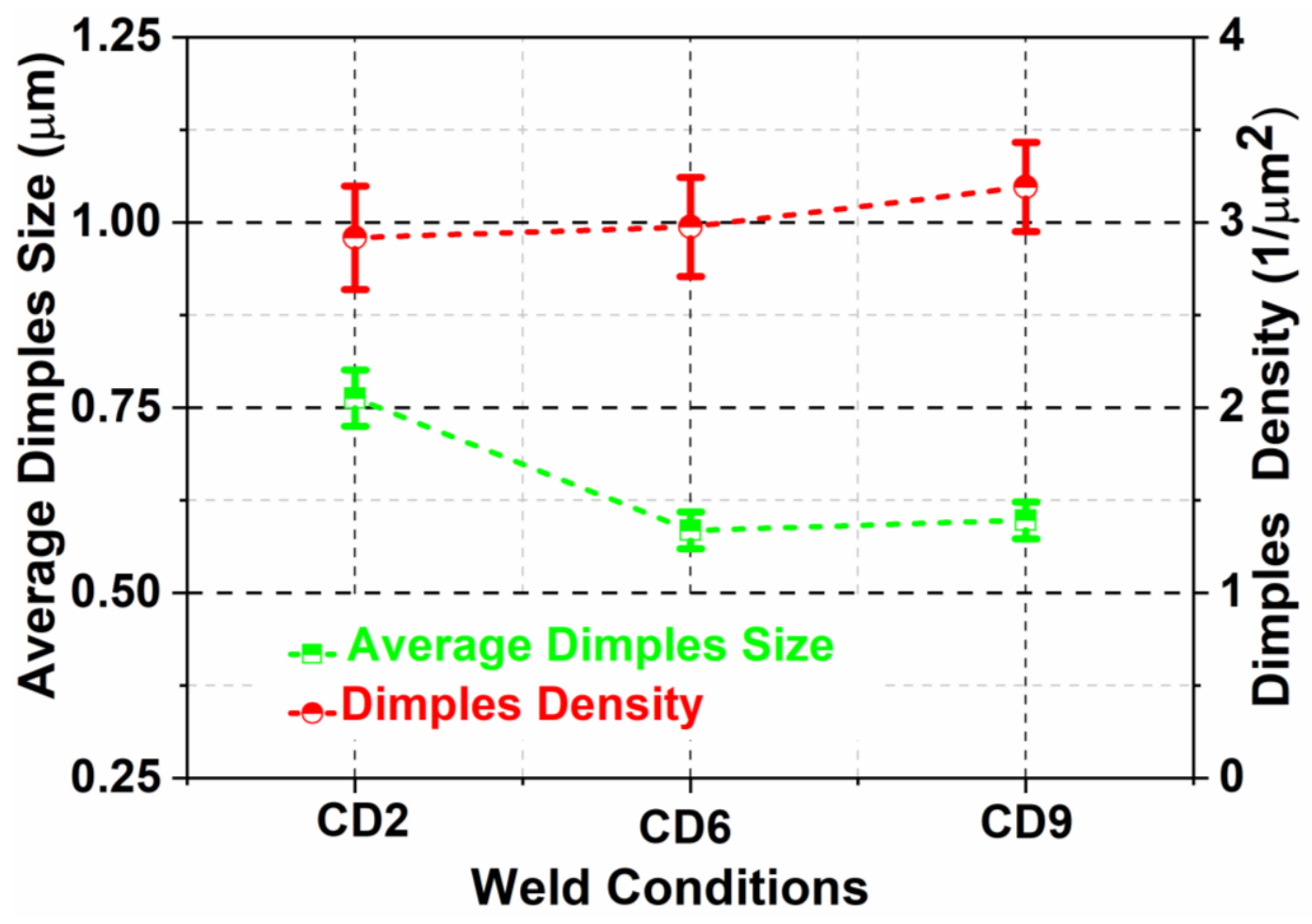

579 Fig. 10. Variation in the measured dimple size and density as a function of weld conditions. 
Tables

581 Table 1. The identity and ranges of RFW process parameters implemented during CDW in 582 this study.

\begin{tabular}{cccc}
\hline Specimen & $\begin{array}{c}\text { Rotational speed } \\
\text { (RPM) }\end{array}$ & $\begin{array}{c}\text { Friction force } \\
(\mathbf{k N})\end{array}$ & $\begin{array}{c}\text { Forge force } \\
(\mathbf{k N})\end{array}$ \\
\hline CD1 & $800-1000$ & $275-325$ & $450-500$ \\
CD2 & $800-1000$ & $325-375$ & $600-650$ \\
CD3 & $800-1000$ & $375-425$ & $700-750$ \\
CD4 & $1000-1200$ & $275-325$ & $600-650$ \\
CD5 & $1000-1200$ & $325-375$ & $700-750$ \\
CD6 & $1000-1200$ & $375-425$ & $450-500$ \\
CD7 & $1200-1400$ & $275-325$ & $700-750$ \\
CD8 & $1200-1400$ & $325-375$ & $450-500$ \\
CD9 & $1200-1400$ & $375-425$ & $600-650$ \\
\hline
\end{tabular}

583 

Journal of Manufacturing Science and Engineering

584 Table 2. Strain hardening exponents and hardening capacity for the BM and the welds

\begin{tabular}{cccc}
\hline Condition & $\boldsymbol{n}_{\mathbf{1}}$ & $\boldsymbol{n}_{\mathbf{2}}$ & $\boldsymbol{H}_{\mathbf{c}}$ \\
\hline BM & 0.336 & 0.187 & 0.280 \\
CD1 & 0.172 & 0.088 & $0.205 \pm 0.004$ \\
CD2 & 0.169 & 0.092 & $0.209 \pm 0.007$ \\
CD3 & 0.167 & 0.105 & $0.227 \pm 0.001$ \\
CD4 & 0.165 & 0.095 & $0.226 \pm 0.005$ \\
CD5 & 0.165 & 0.094 & $0.213 \pm 0.004$ \\
CD6 & 0.159 & 0.093 & $0.220 \pm 0.002$ \\
CD7 & 0.175 & 0.102 & $0.208 \pm 0.005$ \\
CD8 & 0.177 & 0.095 & $0.219 \pm 0.002$ \\
CD9 & 0.170 & 0.101 & $0.214 \pm 0.004$
\end{tabular}

585 

Journal of Manufacturing Science and Engineering

586 Table 3. Maximum hardness values obtained for the WZ of all the welds produced under 587 different conditions.

\begin{tabular}{cccccccccc}
\hline Welds & CD1 & CD2 & CD3 & CD4 & CD5 & CD6 & CD7 & CD8 & CD9 \\
Maximum HV & 693 & 686 & 699 & 683 & 702 & 716 & 683 & 661 & 673
\end{tabular}


589 Table 4. Summary of the calculated values for the ANOVA parameters

\begin{tabular}{|c|c|c|c|c|c|c|}
\hline Source & $\begin{array}{l}\text { Degree of } \\
\text { freedom }\end{array}$ & $\begin{array}{l}\text { Sum of } \\
\text { squares }\end{array}$ & $\begin{array}{l}\text { Mean of } \\
\text { squares }\end{array}$ & F-test & P-test & $\begin{array}{c}\text { Contribution } \\
\text { (\%) }\end{array}$ \\
\hline Rotational speed & 2 & 303.69 & 151.84 & 2.99 & 0.251 & 59.66 \\
\hline Friction force & 2 & 103.08 & 51.54 & 1.01 & 0.496 & 20.25 \\
\hline Forge force & 2 & 0.685 & 0.342 & 0.01 & 0.993 & 0.13 \\
\hline Residual error & 2 & 101.57 & 50.78 & & & 19.95 \\
\hline Total & 8 & 509.02 & & & & 100 \\
\hline
\end{tabular}

590 
Journal of Manufacturing Science and Engineering

591 